\title{
Como o clipping pode auxiliar o dermatologista *
}

\author{
How the Nail Clipping helps the dermatologist
}

José Fillus Neto ${ }^{1}$

\author{
Ana Maria Tchornobay ${ }^{2}$
}

\begin{abstract}
Resumo: Alterações ungueais são queixas muito frequentes nos consultórios dermatológicos. Onicomicoses representam cerca de 50\% das onicopatias, daí a importância de se estabelecer o diagnóstico correto antes de se iniciar o tratamento. Neste artigo, relataremos a utilidade de um exame que é de fácil execução pelo clínico, de baixo custo e sensível: esse exame consiste na análise histopatológica da queratina ungueal distal, atualmente já consagrado com o termo clipping.

Palavras-chave: Doenças da unha; Doenças da unha/diagnóstico; Onicomicose; Onicomicose/diagnóstico; Onicomicose/patologia
\end{abstract}

\begin{abstract}
Onycodystrophies are common problems in dermatologic practice. About $50 \%$ of dystrophic nails have a fungal cause, so it is very important to establish a correct diagnosis before treatment. In this article we relate the usefulness of an easydoing exam, free from pain, cheap and sensible. This exam is the histopathology of the nail keratin or nail clipping.

Keywords:Nail diseases; Nail diseases/diagnosis; Onychomycosis; Onychomycosis/diagnosis; Onychomycosis//pathology
\end{abstract}

\section{INTRODUÇÃO}

$\mathrm{Na}$ dermatologia, chamamos de clipping os fragmentos cortados da parte distal da lâmina ungueal para avaliação histopatológica.

O clipping surgiu da necessidade de se obter histologicamente uma resposta rápida, de baixo custo e indolor para identificar alterações na lâmina ungueal que possam expressar uma patologia do aparelho ungueal. Uma das indicações, talvez a mais procurada, surge quando temos na clínica alterações compatíveis com onicomicose, porém com exames micológicos repetidamente negativos. Outras situações também podem ser avaliadas pela análise histológica da queratina ungueal, como psoríase, líquen plano, traumas, discromias, melanoníquias e mesmo tumores. No caso das alterações pigmentares, o exame pode definir o tipo e a localização da origem do pigmento, orientando o dermatologista para o local mais correto da biópsia e possibilitando, assim, menos sequelas para a matriz ungueal.

\section{RELATO DO CASO}

Mulher de 45 anos que apresentava, há oito meses, onicólise látero-distal em hálux direito com dois exames micológicos (direto e cultura) negativos. Foi realizado um clipping (Figura 1).

\section{Laudo histopatológico:}

Cortes histológicos de lâmina ungueal exibem áreas de paraceratose, alguns lagos serosos e hiperceratose em área ventral. Ausência de células inflamatórias. A pesquisa para fungos é positiva, com a presença de esparsos agrupamentos de hifas distribuídas irregularmente, com paredes delicadas, diâmetros variáveis, sugestivo de fungo não dermatofítico (Figura 2).

Coloração especial realizada - PAS-diastase resistente

Você sabe como se faz um clipping?

Trata-se de um exame muito simples de se rea-

Recebido em 30.01.2009.

Aprovado pelo Conselho Consultivo e aceito para publicação em 24.03.09.

* Trabalho realizado no Serviço de Dermatologia da Universidade Federal do Paraná (UFPR) - Curitiba (PR), Brasil.

Conflito de interesse: Nenhum / Conflict of interest: None

Suporte financeiro: Nenhum / Financial funding: None

Mestre em patologia pela Universidade Federal Fluminense (UFF). Professor de patologia médica, adj. IV, área de dermatopatologia do Hospital de Clínicas da Universidade Federal do Paraná (UFPR) - Curitiba (PR), Brasil.

Dermatologista, médica voluntária do Serviço de Dermatologia da Universidade Federal do Paraná (UFPR) - Curitiba (PR), Brasil

(C)2009 by Anais Brasileiros de Dermatologia

An Bras Dermatol. 2009;84(2):173-6. 


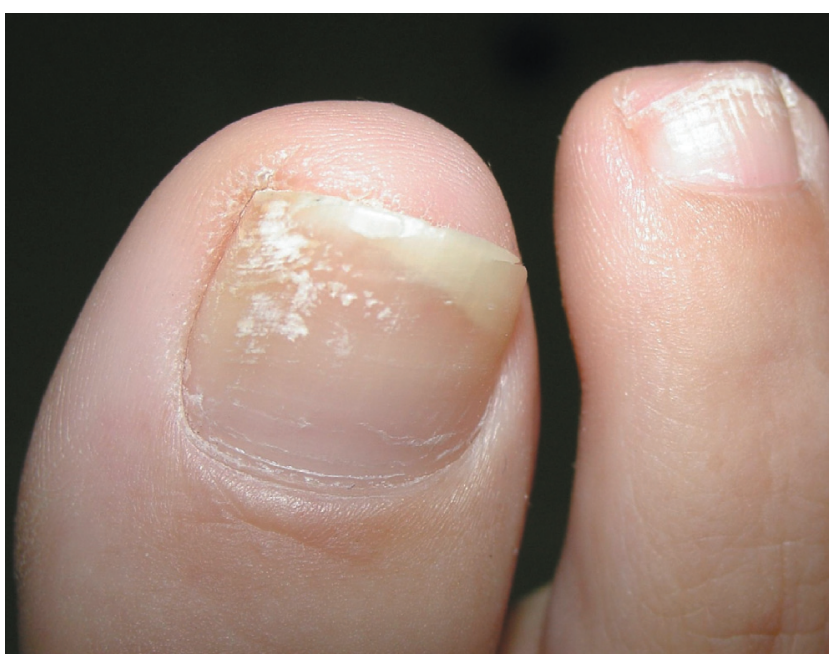

FIGURA 1: Hálux direito com alteração ungueal; onicólise látero-distal

lizar em consultório. Basta cortar um fragmento da parte distal da unha afetada que tenha no mínimo $5 \mathrm{~mm}$ no sentido horizontal da lâmina. Embora alguns autores achem $3 \mathrm{~mm}$ suficientes, 1 em nossa experiência, $5 \mathrm{~mm}$ ou mais são o ideal (Figura 3). Muito importante é a largura do fragmento, que deve ter, no mínimo, $2 \mathrm{~mm}$, pois a fixação do fragmento na parafina depende bastante desse detalhe. Se a lâmina ungueal for muito dura e espessa, poderá ser amolecida em imersão durante alguns minutos em água morna. Se a unha estiver muito curta, valerá a pena esperar alguns dias para o seu crescimento.

\section{Você sabe como enviar o material obtido por} clipping para o Serviço de Anatomia Patológica?

Basta colocar o fragmento em um frasco vazio, envelope ou saco plástico. Alguns autores sugerem colocar em solução de formol a $10 \%$, porém, em

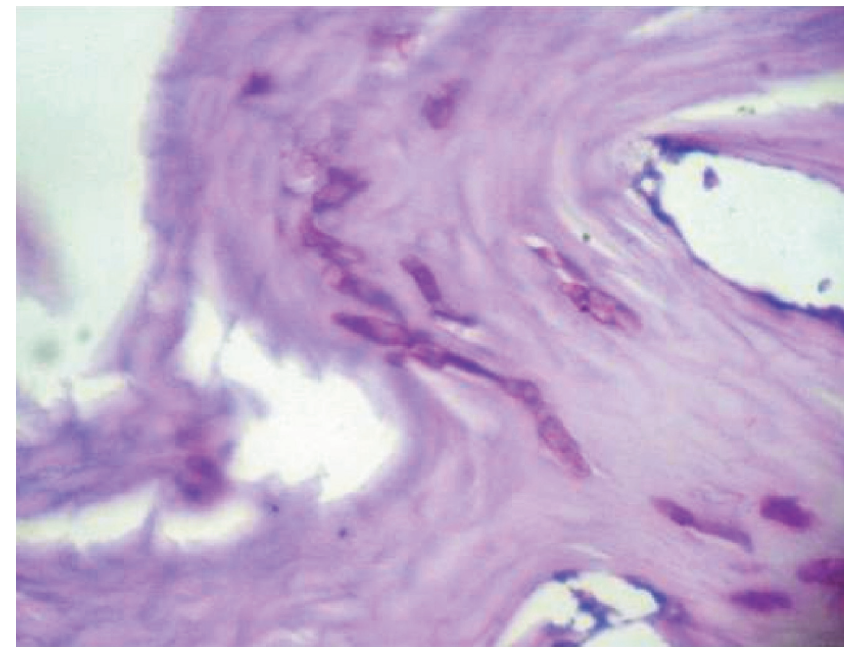

FIGURA 2: Hifas não uniformes na lâmina ungueal (PAS-CD 400x) nossa experiência, bem como na opinião de alguns autores, isso não é necessário. ${ }^{2}$

\section{O patologista e o clipping}

Clippings ungueais, assim como biópsias ungueais, são materiais dos mais difíceis a partir dos quais se possam obter preparados histológicos, dentro da dermatopatologia. São inúmeros os métodos e tentativas para se conseguir que o tecido ungueal se torne mais fácil de cortar. Utilizam-se diversas substâncias tidas como possíveis amolecedoras da queratina, porém nenhuma se mostrou satisfatória até agora, havendo, em nossa experiência, bastante discrepância quando são testadas. As mais usadas são $\mathrm{KOH}$ a $20 \%$, solução aquosa de Tween 40 a $10 \%$ e metacrilato. ${ }^{3}$ Alguns patologistas preconizam cortes histológicos do fragmento ungueal diretamente incluído em parafina, sem nenhum tratamento prévio e sem amolecedores. Esse método foi por nós adotado, com a obtenção de bons preparados histológicos. Rotineiramente, as lâminas são coradas por hematoxilina-eosina e PASdiastase resistente ou PAS-CD (PAS - Com Digestão), deixando-se duas lâminas em branco para posteriores colorações, se necessário. Na microscopia, o patologista pode evidenciar, dependendo da etiologia, alterações como paraceratose, lagos serosos, corpos citoides, fungos (hifas, pseudo-hifas, artroconídeos e blastoconídeos), pigmentos, sangue, bactérias, ácaros e até corpos estranhos. ${ }^{4}$ Quando as hifas são alteradas por tratamentos, pode haver dificuldade com a coloração de PAS-CD; então, utilizamos a técnica de metaminato de prata (Grocott), que pode esclarecer algumas dúvidas. Se necessário, podemos realizar colora-
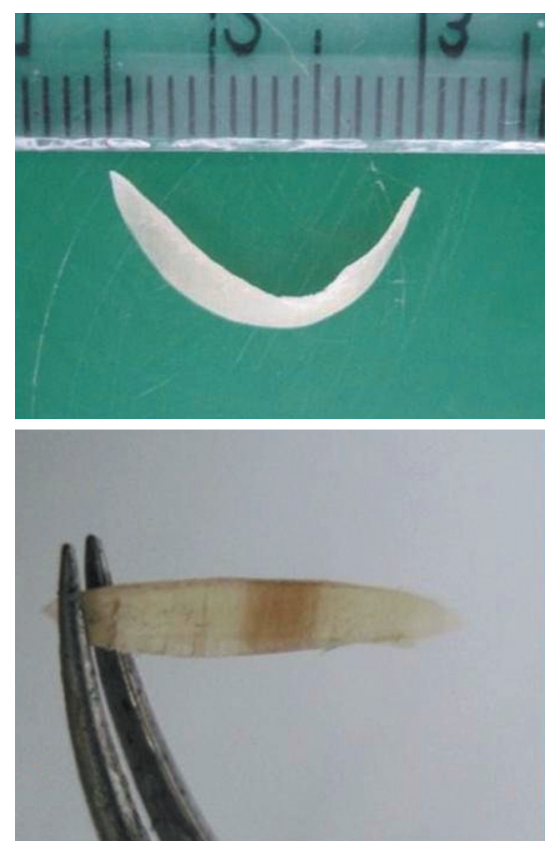

Figura 3:

A - Fragmento distal da lâmina ungueal (clipping)

B - Fragmento distal da lâmina ungueal com melanoníquia estriada (clipping) 
ção para pigmento melânico, que, além de definir se ele é mesmo melânico, o situa na lâmina, orientando o clínico sobre seu local de origem: se na face superficial da lâmina, origem na matriz proximal; se na face ventral, origem na matriz distal, o que facilita a escolha do local mais adequado para a biópsia.

\section{Você sabe interpretar um laudo histopatológico de um clipping?}

Vamos comparar os achados descritos no laudo pelo patologista com a história e o exame clínico. A presença de paraceratose, lagos serosos, hiperceratose e células inflamatórias (neutrófilos) pode ser observada nas onicomicoses e na psoríase (Figuras 4 e 5). Achados semelhantes também são encontrados em eczemas e alterações traumáticas, porém sem as células inflamatórias.

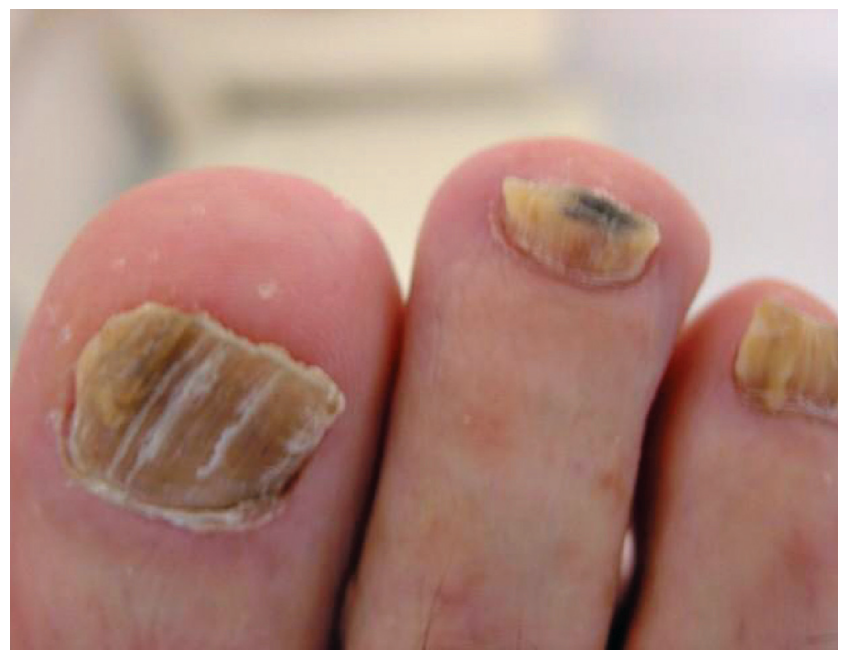

Figura 4: Psoríase ungueal
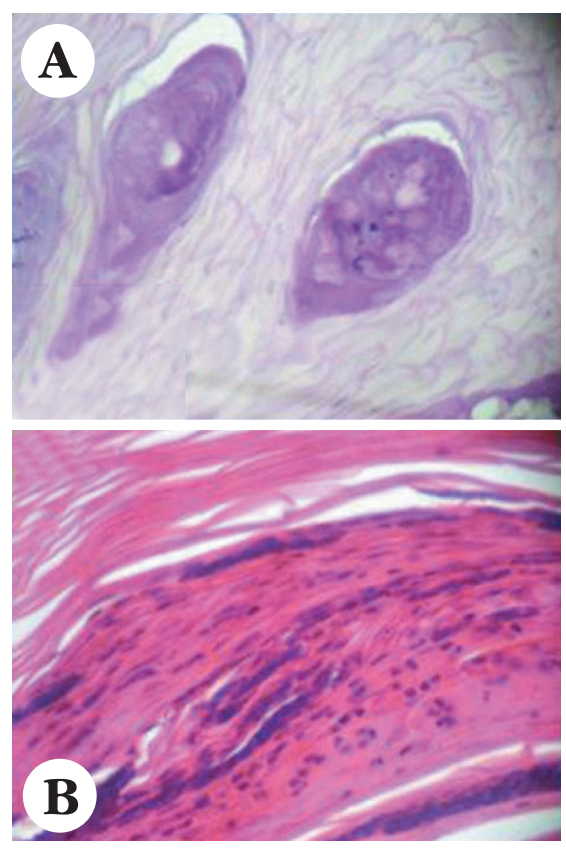

Figura 5: A

Lagos serosos (PAS-CD 400x) B - Neutrófilos em meio a paraceratose (HE 400x)
A presença de hifas septadas e uniformes invadindo a lâmina sugere infecção por dermatófitos (Figura 6). Hifas com paredes mais espessas e tortuosas podem representar fungos não dermatófitos $\mathrm{e}$, nesses casos, é recomendável fazer nova cultura, orientando o laboratório para usar meios apropriados para o cultivo de fungos não dermatófitos. Isso também pode ajudar a explicar os casos que não respondem ao tratamento, já que esses fungos costumam ser resistentes aos antifúngicos. ${ }^{5}$

Conídeos na face ventral da lâmina, principalmente, se acompanhados de brotamentos e pseudohifas, podem indicar infecção por cândida e, nesse caso, a cultura se torna muito importante para identificação do gênero e da espécie. Hifas com aspecto degenerado e artroconídeos isolados podem ocorrer em consequência de medicamentos antifúngicos já utilizados. ${ }^{5}$ Colônias bacterianas, se grandes, merecem investigação por meio de cultura e bacterioscopia. A presença de hemácias é compatível com lesões traumáticas e pode ser um achado valioso para afastar outras discromias. $\mathrm{O}$ achado de pigmento melânico na lâmina ungueal confirma o diagnóstico de melanoníquia (Figura 7).

\section{VOCÊ CONHECE ESTES DADOS?}

Sinais presentes nas onicomicoses, como onicólise, leuconíquia, melanoníquia e distrofia total, também ocorrem em outras doenças ungueais, como psoríase, líquen plano, farmacodermias e alterações traumáticas. Estima-se que as onicomicoses representem cerca de $50 \%$ das onicopatias. O diagnóstico dessas infecções, que deveria ser simples, não o é, na prática, por motivos variados, como: coleta inadequada,
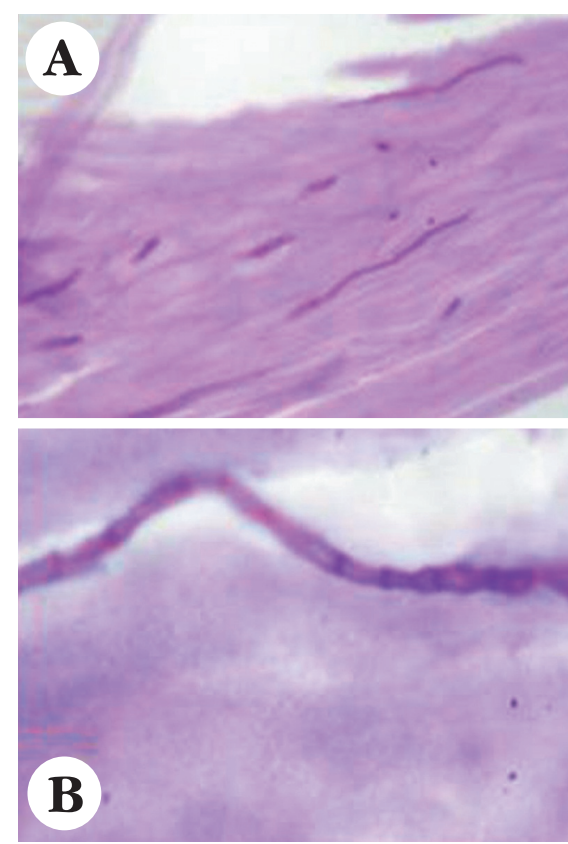

Figura 6: A - Hifas uniformes, septadas, sugestivas de dermatófito (PAS-CD 400x) B - Hifa longa, uniforme e septada; dermatófito (PAS-CD 1000x) 


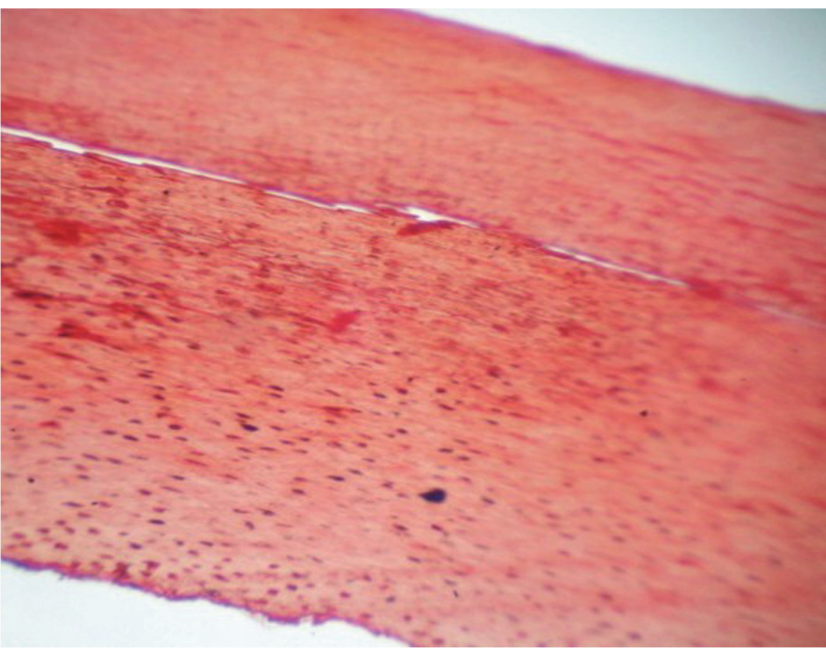

Figura 7: Melanoníquia. Pigmento negro, delicado e esparso na zona ventral da lâmina ungueal, proveniente da matriz distal. Fontana Masson.

presença de contaminantes, inexperiência dos técnicos no preparo e na identificação dos fungos e uso indiscriminado de medicamentos pelos pacientes. A repetição dos exames nem sempre é possível, muitas vezes, por razões socioeconômicas. O tratamento das onicomicoses, além de ser longo, é caro e pode estar associado a efeitos adversos e interagir com outras drogas, devendo, por isso, ser indicado apenas na certeza do diagnóstico. ${ }^{6}$ Há poucos estudos de diagnóstico de onicopatias feitos por meio de clipping e pouca familiaridade dos patologistas com o assunto. Por sua vez, os dermatologistas também não estão habituados a realizar esse exame em consultório e têm dificuldade para interpretar o laudo histopatológico. A técnica histológica também pode ser prejudicada por coleta inadequada e tamanho insuficiente da amostra. ${ }^{7}$ No entanto, como vimos, trata-se de um exame de fácil execução, baixo custo e rápida resposta, se comparado com o tempo de espera de uma cultura para fungos. Também é um exame indolor para o paciente, não deixa sequela e tem alta sensibilidade. Pode ser um valioso auxiliar na escolha do local a ser biopsiado no caso de melanoníquias e é muito importante na avaliação de doenças como psoríase e líquen plano, quando estas se manifestam exclusivamente nas unhas. A análise histopatológica do clipping não é um substituto da cultura, a qual continua sendo o "padrão-ouro" no diagnóstico das onicomicoses devido a sua alta especificidade. ${ }^{8}$

\section{REFERÊNCIAS}

1. Suarez SM, Silvers DN, Scher RK, Pearlstein HH, Auerbach R. Histologic Evaluation of nail clippings for diagnosing onychomycosis. Arch Dermatol. 1991;127:1517-9.

2. Piérard GE, Arrese JE, Pierre S, Bertrand C, Corcuff P, Lévêque JL, et al. [Microscopic diagnosis of onychomycoses]. Ann Dermatol Venereol. 1994;121:25-9.

3. Magalhães MG, Succi ICB, Sousa MAJ. Subsídios para estudo histopatológico das lesões ungueais. An Bras Dermatol. 2003;78:49-61.

4. Jerasutus S. Histology and histopathology. In: Scher RK, Daniel III CR, editors. Nails therapy-diagnosis-surgery. 3rd ed. Philadelphia: Elsevier Saunders; 2005. p.37-51.

5. Chauvin MF, Lacroix C. Diagnostic differential des onychomycoses. Ann Dermatol Venereol. 2003; 130:1248-3.

6. Reisberger EM, Abel C, Landthaler M, Szeimies RM. Histopathological diagnosis of onichomycosis by periodic acid-Schiff-stained nail clippings. $\mathrm{Br} \mathrm{J}$ Dermatol. 2003;148:749-4.

7. Zanardi D, Nunes DH, Pacheco AS, Tubone MQ, Souza Filho JJ. Avaliação dos métodos diagnósticos para onicomicose. An Bras Dermatol. 2008;83:119-4.

8. Lawry MA, Haneke E, Strobeck K, Martin S, Zimmer B, Romano PS. Methods for diagnosing onychomycosis: a comparative study and review of the literature. Arch Dermatol. 2000;136:1112-6.

ENDEREÇO PARA CORRESPONDÊNCIA / MAILING ADDRESS: José Fillus Neto

Rua Voluntários da Pátria, 475, $6^{\circ}$ andar, sala 605 - Ed. Asa Centro 80020926 Curitiba PR

Tel./fax: 55 (41) 323524

E-mail:jfn@netpar.com.br

Como citar este arquivo / How to cite this article: Fillus Neto J, Tchornobay AM. Como o clipping pode auxiliar o dermatologista. An Bras Dematol. 2009;84(2):173-6. 